\title{
The feasibility parameters quantification FMECA algorithm based on fuzzy theory
}

\author{
Lv YanMei ${ }^{*}$, Zhen HongTao and Zhang Dong \\ Machine Technology Research Institute, Machine Engineering College \\ Shijiazhuang, China, 050000 \\ lymemail163@163.com
}

\begin{abstract}
Keywords: FMECA; The fuzzy theory; RPN; The feasibility of parameters; UAV
Abstract: According to the optimization problem in a variety of corrective and improvement actions that exist in the FMECA method, this paper introduces the fuzzy theory of FMECA analysis, study quantitative method of the degree of severity $\mathrm{S}$, occurrence probability $\mathrm{O}$ and detestability D of RPN algorithm, and introduce the concept of feasible parameter, based on the RPN values change before and after the implementation of corrective actions and feasibility of the ratio of the corrective measures to select parameters, enhance the accuracy of FMECA analysis, taking UAV as the research object, which improved the effect of FMECA method in the application of the UAV.
\end{abstract}

\section{Introduction}

Failure Mode Effects and Criticality Analysis (FMECA) is an Analysis system of each unit for all possible failure modes and all of the possible effects on the system, and according to the severity of each failure mode, degree of difficulty detecting and classifying an inductive analysis method of frequency. The purpose of which is according to the system failure mode of risk priority number (RPN) value, the size of the weak link of system improvement measures, and predict or tracking improvement measures after the effectiveness of the risk priority number (RPN), make the RPN reach an acceptable level, and improve the quality and reliability of the system. RPN analysis including the Severity grade (S) of failure mode analysis, failure mode probability level (O) analysis and failure mode detected difficulty level (D) analysis. Even the product of RPN is the three parts, namely $R P N=S \times O \times D$.

RPN reflect a comprehensive measure of the possibility and severity of the consequences of failure mode occurs. The greater the RPN value, that the process failure mode of the greater harm.

If wanted to reduce the RPN value, we can start from reducing S、O and D. Reduced the same failure mode corresponds to the RPN value, there were many kinds of methods, how to choose the suitable method is a more important question. Reference [1] in FMECA in several can reduce the RPN's correction method to choose the appropriate corrective methods are studied, put forward the feasibility of corrective measures F (F and security, costs, resources, time, quality and reliability and other factors), the concept of for a failure mode, identified some corrective measures before and after the RPN variation and the greater the ratio of $\mathrm{F}$ is the correction measures the better corrective action selection method. And Reference [2] to counter the problem of how to determine the feasibility of corrective measures F, based on the known Pareto Priority Index calculation program, to study the assessment method of F. Reference [3] proposed a kind of factors related to F (such as cost, time consumption, chances, etc.) of the geometric average as a way to $F$ values. Reference [4] for the risk assessment of traditional FMECA expert judgment fuzziness and uncertainty in the process of problem, put forward based on the dependence of linguistic ordered weighted geometric (DLOWG) operator FMECA risk assessment methods.

Based on the research of the above documents all sorts of RPN value selection methods, this paper put forward the quantitative method of feasibility parameter $F$ based on fuzzy measure, quantified the feasibility of the parameters by using the method of fuzzy mathematics, then according to the variation of RPN before and after a corrective action and feasibility of the 
parameters of $\mathrm{F}$ ratio as the basis of selecting some corrective actions.

\section{The quantitative evaluation of Severity $S$, occurrence probability $O$ and detestability $D$}

Center of mass to the center of mass of fuzzy method to fuzzy number $\bar{A}$ is defined as its to fuzzy numerical computation formula is as follows:

$$
\bar{x}_{0}(\bar{A})=\frac{\int_{a}^{d} x u_{\& \alpha}(x) d x}{\int_{a}^{d} u_{\& \alpha}(x) d x}
$$

Where, $\bar{x}_{0}(\bar{A})$ is centroid values of fuzzy number $\bar{A} ; u_{\&}(x)$ is the membership function of $\bar{A}$.

If a fuzzy number $\bar{A}$ is represented by $\alpha$ cut set, said that $\bar{A}=\cup_{\alpha} \alpha \square(A)_{\alpha}=\cup_{\alpha} \alpha\left[(x)_{\alpha}^{L}(x)_{\alpha}^{U}\right]$, $(0<\alpha \leq 1)$, when $\Delta \alpha_{i}=\frac{1}{n}, \alpha_{i}=\frac{i}{n}, i=0, \cdots, n$, excepted the fuzzy values by type (1) $\sim$ type (3) :

$$
\begin{gathered}
\int_{a}^{d} \mu_{\&}(x) d x=\frac{1}{2 n}\left[(x)_{a_{0}}^{U}-(x)_{a_{0}}^{L}\right]+\frac{1}{2 n}\left[(x)_{a_{n}}^{U}-(x)_{a_{n}}^{L}\right]+\frac{1}{n} \sum_{i=1}^{n-1}\left[(x)_{a_{i}}^{U}-(x)_{a_{i}}^{L}\right] \\
\int_{a}^{d} x \mu_{\& d}(x) d x=\frac{1}{6 n}\left[(x)_{a_{0}}^{2 U}-(x)_{a_{0}}^{2 L}\right]+\frac{1}{6 n}\left[(x)_{a_{n}}^{2 U}-(x)_{a_{n}}^{2 L}\right]+\frac{1}{3 n} \sum_{i=1}^{n-1}\left[(x)_{a_{n}}^{2 U}-(x)_{a_{n}}^{2 L}\right]+\frac{1}{6 n} \sum_{i=1}^{n-1}\left[(x)_{a_{i}}^{U}\left[(x)_{a_{i+1}}^{U}-(x)_{a_{i}}^{L}(x)_{a_{i+1}}^{L}\right](3)\right.
\end{gathered}
$$

Reference [5] according to the type (1) to (3) combined with fuzzy theory to calculate the basic steps of the risk of failure mode of three parameters:

(1) Through (4) (6) expert member of subjective opinions, calculating the overall occurrence of each failure mode, severity, detection, and the overall fuzzy weights of S, O, D.

$$
\begin{aligned}
& R_{i j}^{\beta / O}=\sum_{j=1}^{m} k_{j} R_{i j}^{\circ o}=\left(\sum_{j=1}^{m} k_{j} R_{i j L}^{o}, \sum_{j=1}^{m} k_{j} R_{i j M}^{o}, \sum_{j=1}^{m} k_{j} R_{i j U}^{o}\right), \\
& i=1, \square, n \mathfrak{h} \%=\sum_{j=1}^{m} k_{j} \mathscr{Q}_{j}=\left(\sum_{j=1}^{m} k_{j} w_{j L}^{o}, \sum_{j=1}^{m} k_{j} w_{j M}^{o}, \sum_{j=1}^{m} k_{j} w_{j U}^{o}\right) \\
& R_{i j}^{\delta}=\sum_{j=1}^{m} k_{j} R_{i j}^{\delta}=\left(\sum_{j=1}^{m} k_{j} R_{i j L}^{S}, \sum_{j=1}^{m} k_{j} R_{i j U}^{S}, \sum_{j=1}^{m} k j R_{i j U}^{S}\right), \\
& i=1, \cdots, n \text { 各 }=\sum_{j=1}^{m} k_{j} \text { 謄 }=\left(\sum_{j=1}^{m} k_{j} w_{j L}^{S}, \sum_{j=1}^{m} k_{j} w_{j M}^{S}, \sum_{j=1}^{m} k_{j} w_{j U}^{S}\right) \\
& R_{i j}^{\beta / Q}=\sum_{j=1}^{m} k_{j} R_{i j}^{\ell}=\left(\sum_{j=1}^{m} k_{j} R_{i j L}^{D}, \sum_{j=1}^{m} k_{j} R_{i j M}^{D}, \sum_{j=1}^{m} k_{j} R_{i j U}^{D}\right)
\end{aligned}
$$

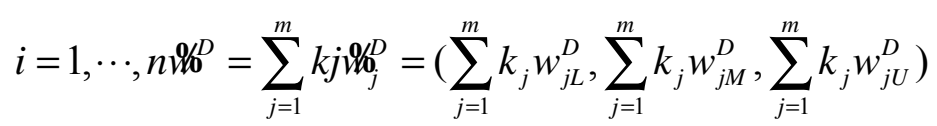

(2) By corresponding formula for each failure mode defines fuzzy risk priority value $R P N_{i}$ and its $\alpha$ cut set.

(3) Through the center of mass to the blur method make the form of fuzzy number $R P N_{i}$ into the accurate values. When unit $[0,1]$ interval by different values $\alpha$, such as centroid values of fuzzy number $R P N_{i}$ can be determined.

(4) Based on the centroid values of fuzzy number $R P N_{i}$, risk for each failure modes to sort.

\section{Risk priority sorting method}

Above studied how to calculate the three parameters of the severity of the risk priority, the 
probability and detection can be quantified method, and obtained the corresponding failure mode of risk priority value. Selection based on this, this article need to study which fault mode first to make FMECA decision, aiming at this problem, used a decision-making method called Scree --Plot, this method first put all the failure mode of RPN values in the order since the childhood, then all the failure mode of RPN scatter plot annotate, its diagram is shown in figure 1.

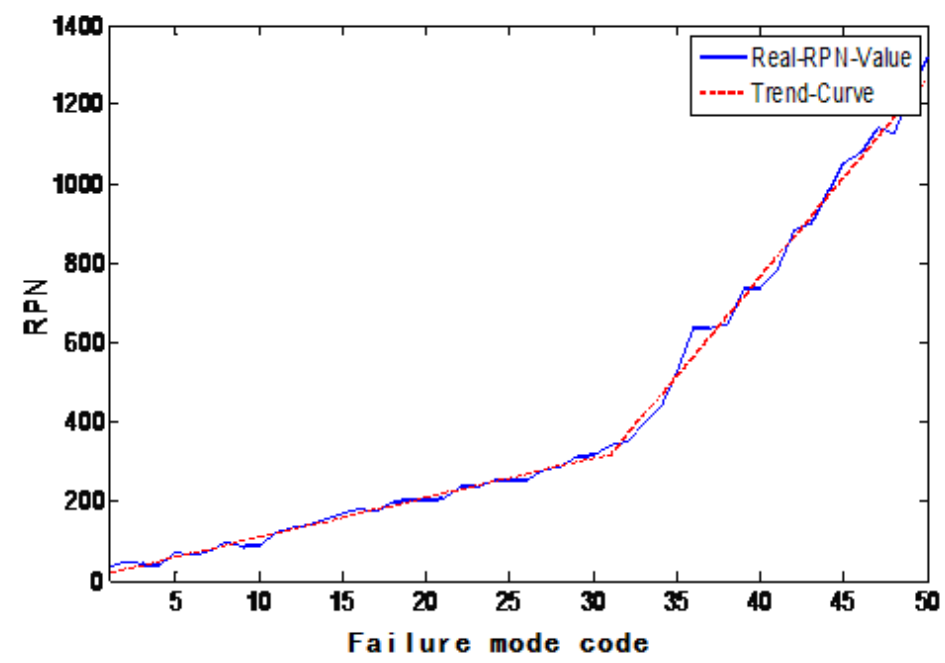

Fig.1 RPN value of the Scree--Plot

As shown in figure.1, the solid line shows the corresponding failure mode of the RPN values, dotted line paragraphs RPN values corresponding to different changing trends. Can be seen from the diagram, the first 30 or so of RPN value change trend is not obvious, basic in a relatively stable within the range of change, and then 20 RPN value tendency obviously, change the slope is very high, RPN value in the range of the segment from a smaller values into a larger value, reference [6] is the segment interval corresponding RPN value as the primary processing to failure mode, and then from the segment interval corresponding to the maximum RPN value of processing, processing from the biggest RPN value to the smallest RPN value, this is the Scree-- plot method is used to determine the first need to deal with the basic process of failure mode. Because of this method is intuitive, simple, easy to understand, therefore, the article adopts the method of the RPN priority selection.

\section{The quantitative method of feasibility parameters}

When the failure mode of identified the need to prioritize, the methods to choose the need to reduce the RPN values. Reduce the same failure mode corresponds to the RPN value, there are many kinds of methods, how to choose the suitable method is a more important question. In this paper, based on the study of the various selection RPN value method, is proposed based on the feasibility of fuzzy metric parameters $\mathrm{F}$ quantitative method, the feasibility of the parameters by using the method of fuzzy mathematics to quantify, then according to the variation of RPN before and after a corrective action and feasibility of the parameters of $F$ ratio as the basis of selecting some corrective measures, calculation methods such as shown in (7).

$$
R E F_{\text {_ value }}=\frac{R P N_{\text {iBefore }}-R P N i_{\text {After }}}{F_{i}}=\frac{\Delta R P N}{F_{i}}
$$

In formula(7), $R P N_{\text {iBefore }}$ stands for corrective measures before the corresponding RPN certain failure mode; $R P N_{i A f t e r}$ stands for corrective measures to the corresponding RPN later this kind of failure mode; $\triangle R P N$ stands for corrective measures before and after the change of RPN; $F_{i}$ is the corrective measures feasibility parameters for this kind of failure mode corresponding. 
Based on the fuzzy theory, the quantitative of feasibility parameters of FMECA algorithm is shown in figure 2 .

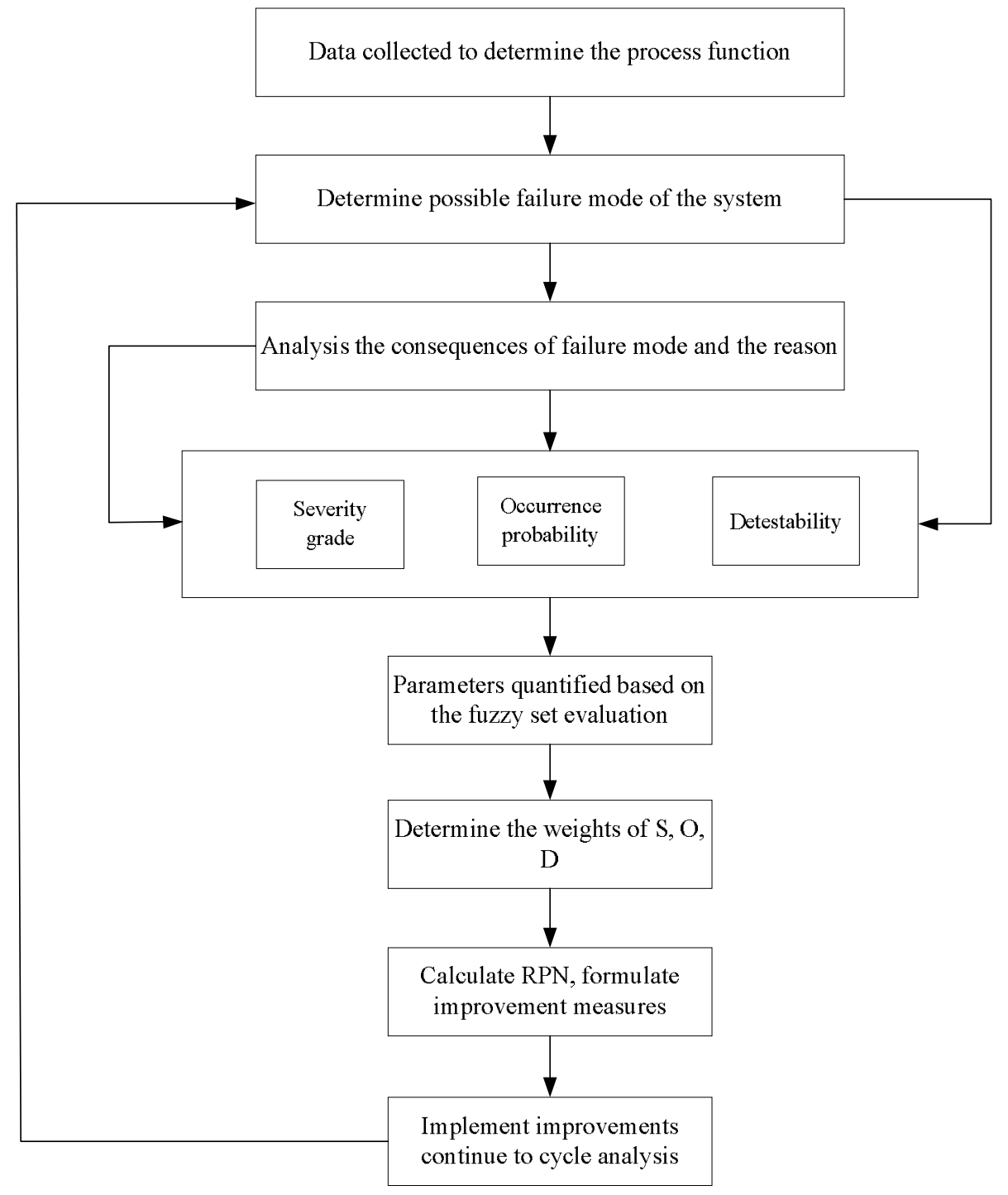

Fig. 2 The quantitative of feasibility parameters FMECA algorithm based on fuzzy theory

\section{UAV avionics subsystem hazard degree analysis}

UAV avionics subsystem is a relatively important subsystem, because of its mechanism of complex, all kinds of transmission mechanism and signal, the data processing algorithm changes more complex than for the reliability analysis of the system is generally more difficult to achieve, UAV avionics subsystem of the general block diagram is shown in figure 3. 


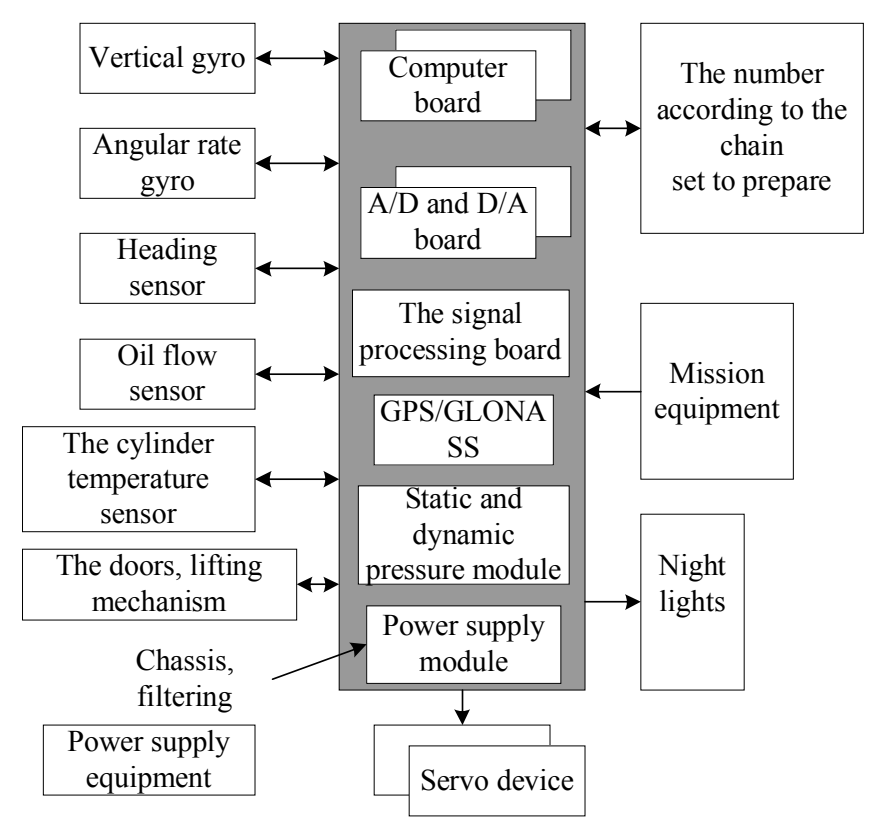

Fig. 3 Avionics system structure diagram

As can be seen from the figure 3, the avionics system is mainly composed of machine plant computers, measuring equipment, servo device, power supply equipment and aircraft electrical system, and detection and security equipment.

The analysis of the structure of the avionic subsystem, on the basis of this paper, the failure mode of each subsystem and its failure reason get FMEA analysis report to sum up, when the FMEA analysis, direct method in the previous section on the influence of the fault severity, the possibility of a possible failure reasons $\mathrm{S}, \mathrm{O}$ and corrective action can be detected easily quantify, in this only to sensor system failure mode and effect analysis of dynamic and static pressure sensor is given as an example analysis report as shown in table 1.

Table 1 FMEA analysis of dynamic and static pressure sensors

\begin{tabular}{|c|l|c|l|c|l|c|c|}
\hline function & $\begin{array}{c}\text { potential } \\
\text { failure mode }\end{array}$ & $\begin{array}{c}\text { seve- } \\
\text { rity }\end{array}$ & failure reason & $\begin{array}{c}\text { size of } \\
\text { possibility }\end{array}$ & corrective action & $\begin{array}{l}\text { detest- } \\
\text { ability }\end{array}$ & PRN \\
\hline $\begin{array}{c}\text { Measure } \\
\text { the plane's } \\
\text { airspeed }\end{array}$ & $\begin{array}{l}\text { The plane's } \\
\text { airspeed } \\
\text { inaccurate } \\
\text { measurement }\end{array}$ & 8 & $\begin{array}{l}\text { Dynamic } \\
\text { pressure sensor } \\
\text { damage }\end{array}$ & 5 & $\begin{array}{l}\text { Fix dynamic } \\
\text { pressure } \\
\text { transducer }\end{array}$ & 3 & 120 \\
\cline { 3 - 8 } & & $\begin{array}{l}\text { Total pressure } \\
\text { pipeline } \\
\text { damaged or } \\
\text { broken }\end{array}$ & 3 & $\begin{array}{l}\text { Repair the total } \\
\text { pipeline }\end{array}$ & 6 & 144 \\
\cline { 3 - 8 } & $\begin{array}{l}\text { Static pressure } \\
\text { pipeline } \\
\text { damaged or } \\
\text { broken }\end{array}$ & 4 & $\begin{array}{l}\text { Fix static } \\
\text { pressure } \\
\text { pipeline }\end{array}$ & 2 & 64 \\
\hline $\begin{array}{c}\text { Measure } \\
\text { the } \\
\text { barometric } \\
\text { altitude of } \\
\text { the plane }\end{array}$ & $\begin{array}{l}\text { The plane's } \\
\text { barometric } \\
\text { altitude } \\
\text { inaccurate } \\
\text { measurement }\end{array}$ & \multirow{2}{*}{6} & $\begin{array}{l}\text { Static pressure } \\
\text { sensor damage }\end{array}$ & 7 & $\begin{array}{l}\text { Fix static } \\
\text { pressure } \\
\text { transducer }\end{array}$ & 2 & 84 \\
\cline { 3 - 8 } & & $\begin{array}{l}\text { Static pressure } \\
\text { pipeline } \\
\text { damaged or } \\
\text { broken }\end{array}$ & 3 & $\begin{array}{l}\text { Repair static } \\
\text { pressure } \\
\text { pipeline }\end{array}$ & 6 & 108 \\
\hline
\end{tabular}


Table 2 Table of corrective measures to optimize

\begin{tabular}{|c|c|c|c|c|c|c|c|c|c|c|c|c|}
\hline \multirow{3}{*}{$\begin{array}{l}\text { potential } \\
\text { failure mode }\end{array}$} & \multirow{3}{*}{$\begin{array}{c}\text { Possible } \\
\text { corrective actions }\end{array}$} & \multicolumn{8}{|c|}{$\begin{array}{l}\text { The current }(\mathrm{C}) \text { and after improvement }(\mathrm{I}) \\
\text { values of the parameters }\end{array}$} & \multirow{3}{*}{$\mathrm{F}$} & \multirow{3}{*}{ ratio } & \multirow{3}{*}{ priority } \\
\hline & & \multicolumn{2}{|c|}{$\mathrm{S}$} & \multicolumn{2}{|c|}{$\mathrm{O}$} & \multicolumn{2}{|c|}{$\mathrm{D}$} & \multicolumn{2}{|c|}{ RPN } & & & \\
\hline & & $\mathrm{C}$ & I & $\mathrm{C}$ & I & $\mathrm{C}$ & I & $\mathrm{C}$ & I & & & \\
\hline \multirow{3}{*}{$\begin{array}{l}\text { The plane's } \\
\text { airspeed } \\
\text { inaccurate } \\
\text { measurement }\end{array}$} & $\begin{array}{c}\text { Fix dynamic } \\
\text { pressure } \\
\text { transducer }\end{array}$ & 8 & 8 & 5 & 4 & 3 & 5 & 120 & 160 & 4 & 10 & 3 \\
\hline & $\begin{array}{l}\text { Repair the total } \\
\text { pipeline }\end{array}$ & 8 & 8 & 3 & 2 & 6 & 7 & 144 & 112 & 2 & 16 & 2 \\
\hline & $\begin{array}{l}\text { Fix static pressure } \\
\text { pipeline }\end{array}$ & 8 & 8 & 4 & 3 & 2 & 8 & 64 & 112 & 2 & 29 & 1 \\
\hline
\end{tabular}

\section{Results of reliability analysis}

Observation can be seen in table 1, static pressure sensor of avionics system mainly complete the space velocity and pressure height of the UAV measurement, and the reason of causing dynamic and static pressure sensor failure mainly is the dynamic pressure sensor or the breakage of the total pressure piping. Can also be seen from table 1, there are many kinds of methods if you want to reduce some failure modes of RPN, based on the provided above, the method of choosing the biggest change of $R E F$ _value before and after correct method as a corrective action, in order to maximize the probability to improve the reliability of UAV avionics subsystem. Table 2 shows the various corrective measures corresponding values $R E F$ _value, can be seen from table 2, modified the effect of the static pressure piping to bring the most obvious, with the greatest probability to improve the reliability of the system, verify the feasibility of the quantitative of feasibility parameters FMECA algorithm based on fuzzy theory.

\section{Reference}

[1] B. Zigmund, G. Pavel, N. Oren, Expanded FMECA (EFMECA). IEEE RAMS, 2004, 31-36.

[2] B. Hartman, Implementing Quality Improvement. The Juran Report, 2, (1983).

[3] Z. Bluvband, Quality Greatest Hits: Classic Wisdom from the Leaders of Quality. ASQ Quality Press, Milwaukee, Wisconsin, 2002.

[4] Wang Xiao-dun, economists, FMECA wind assessment method based on DLOWG operator. Journal of Zhejiang University (engineering science), 46, (2012), 182-188.

[5] Li Yi-jia, Build the star, based on the quality of submarine pipeline construction period of FMECA and the theory of fuzzy risk analysis. Chinese journal of safety science, 22, (2012), 112-117.

[6] Wei Dong-zheng, Marine equipment based on FMECA fault information processing system. Computer and modernization, 5, (2012), 172-177.

[7] Hong Qiang-gu, Guo Li, FMECA application in a frequency selective circuit fault simulation. Journal of engineering design, 17, (2010), 124-127. 